\title{
Effect of dietary supplementation of a phytogenic blend containing Schisandra chinensis, Pinus densiflora, and Allium tuberosum on productivity, egg quality, and health parameters in laying hens
}

\author{
Seung-Gyu Moon ${ }^{1, a}$, Sung-Kwang Lee ${ }^{1, a}$, Woo-Do Lee ${ }^{1}$, Kai-Min Niu ${ }^{1,2}$, Won-Uk Hwang ${ }^{1}$, \\ Jong-Seok Oh ${ }^{1}$, Damini Kothari ${ }^{1}$, and Soo-Ki Kim ${ }^{1, *}$
}

\author{
* Corresponding Authors: Soo-Ki Kim \\ Tel: +82-2-450-3728, Fax: +82-2-458-3728, \\ E-mail: sookikim@konkuk.ac.kr \\ 1 Department of Animal Science and \\ Technology, Konkuk University, Seoul 05029, \\ Korea \\ 2 Institute of Biological Resource, Jiangxi \\ Academy of Sciences, Nanchang 330029, \\ China \\ a These authors contributed equally to this \\ work. \\ ORCID \\ Seung-Gyu Moon \\ https://orcid.org/0000-0001-5650-6391 \\ Sung-Kwang Lee \\ https://orcid.org/0000-0001-7689-1522 \\ Woo-Do Lee \\ https://orcid.org/0000-0003-4861-4637 \\ Kai-Min Niu \\ https://orcid.org/0000-0002-9756-3517 \\ Won-Uk Hwang \\ https://orcid.org/0000-0002-7793-1650 \\ Jong-Seok Oh \\ https://orcid.org/0000-0002-9442-6226 \\ Damini Kothari \\ https://orcid.org/0000-0003-3627-2377 \\ Soo-Ki Kim \\ https://orcid.org/0000-0003-3499-3330
}

Submitted Aug 4, 2020; Revised Aug 28, 2020; Accepted Nov 8, 2020
Objective: This study was conducted to investigate the supplementary effect of a phytogenic blend (SPA: a mixture containing fermented Schisandra chinensis pomace, fermented Pinus densiflora needle extract, and Allium tuberosum powder in the ratio of 2:2:1) on egg production, egg quality, blood constituents, and visceral organs in laying hens.

Methods: A total of $135 \mathrm{Hy}$-line brown laying hens (48-wk-old) were randomly allocated to three dietary treatments with 5 replicates of 9 hens. The control group (CON) was fed a basal diet (no exogenous SPA addition) and the experimental groups were fed the basal diet containing SPA at the level of $0.1 \%$ and $0.3 \%$ for 6 weeks.

Results: The feed intake was significantly improved in SPA supplemented groups as compared with the control $(\mathrm{p}<0.05)$. However, egg production, daily egg mass, and feed conversion ratio were not different among the dietary treatments $(\mathrm{p}>0.05)$. For egg quality traits, only Haugh unit (HU) was significantly improved in SPA $(0.3 \%)(\mathrm{p}<0.05)$ as compared with other groups. However, $\mathrm{HU}$ was not affected during 4 -wk of storage at $18^{\circ} \mathrm{C}$ among the dietary treatments ( $>0.05)$. Furthermore, SPA supplementation did not affect the blood biochemical constituents except for the phosphate content, which was significantly higher in SPA groups than the CON group $(\mathrm{p}<0.05)$. There were no significant differences in visceral organ characteristics and immune indicators (immunoglobulin $\mathrm{A}[\operatorname{Ig} \mathrm{A}], \operatorname{IgG}$, and $\operatorname{IgM}$ ) in SPA or CON groups.

Conclusion: This study suggested that the supplementation of SPA may have beneficial effects on feed intake and egg quality in laying hens.

Keywords: Laying Hens; Fermented Schisandra chinensis Pomace; Pinus densiflora Needle Extract; Allium tuberosum; Feed Additive

\section{INTRODUCTION}

Antibiotics have been routinely used in farm animal production since mid-1950s to promote their well-being and growth. However, the prolonged and unregulated use of antibiotics have raised a concern of the emergence of antibiotic resistance in the animals' bacteria and from there to bacteria infecting humans [1]. The poultry industry has grown substantially in the direction of improving the productivity with the use of alternative antibiotics to improve growth and feed conversion efficiency as well as to prevent infections [2]. In this context, phytogenic feed additives (PFA) comprising a wide variety of herbs, spices, and plant-derived extract have received considerable attention in poultry diets over other commonly used non-antibiotic growth promoters, such as organic acids and probiotics due to 
their safe and environmentally friendly nature [3-6]. PFA contain several bioactive compounds such as polyphenols, essential oils, saponins, and terpenoids [7], which are reported to have digestion stimulating effects [3], antimicrobial and antioxidant properties [5], and anti-inflammatory potential [8]. Several recent studies indicated that the dietary supplementation of PFA improves productive performance, egg quality, digestibility of nutrients, some blood biochemical constituents, and immune activity in laying hens [3-6,8]. However, the efficacy of these additives is influenced by several factors such as plant species, extract composition, application method and levels, poultry age and breed, and housing conditions $[3,9]$.

Schisandra chinensis (S. chinensis) Baill. of Schisandraceae family is native to Far East of Russia, South of China, and Korea [10]. The fruit of S. chinensis, commonly called as a "five-flavored berry", is rich in lignans, with dibenzocylooctadiene lignans (type A) being the most abundant (80\%). In addition, the berries are rich in phytoestrogens, minerals, vitamins, and essential oils [11]. Research on Schisandra fruit revealed that its active lignan possesses antioxidant, antimicrobial, hepatoprotective, and anti-inflammatory functions $[10,12]$. The inclusion of Schisandra meal in broiler diets was shown to improve meat quality [13] and some blood antioxidant parameters [14].

Pine needles have been traditionally used as supplements in various foods and folk medicine in Asia, specifically in Korea and China [15]. Pine needles exhibit several biological activities, including antimicrobial, antioxidant, antimutagenic, antitumor, and anticholesterol [15-17]. These beneficial properties may be related to their bioactive compounds such as phenolics, flavonoids, and tannins [17]. Recently, several studies indicated the potential of pine needles as natural feed additives in poultry production via their stimulatory effects on the antioxidant status of birds [16,18-21]. However, it was also indicated that the high content of condensed tannins in pine needles might affect the nutrient absorption and protein digestibility in animals [22].

Chinese chive (Allium tuberosum) is widely used for culinary purposes and its application in folk medicine has also increased its popularity in Asia [23]. Chinese chive has been reported to demonstrate antioxidant [23], antimicrobial [24], hepatoprotective [25], and anti-inflammatory [23] activities. The beneficial properties of Chinese chive are attributed mainly to organosulfur compounds, polyphenols, and saponins [26].

To our knowledge, little research reported on the effect of these additives in laying hens. Therefore, the current study was designed to evaluate the effect of Schisandra fruit pomace, pine needles, and Chinese chive supplementation to layer diets on laying performance, egg quality, egg storage, blood constituents, and visceral organs.

\section{MATERIALS AND METHODS}

\section{Preparation of feed additive}

A phytogenic blend was prepared by mixing fermented $S$. chinensis pomace, fermented pine needle extract, and Chinese chive powder in the ratio of 2:2:1 (SPA) based on the preliminary experiments. The $S$. chinensis fruit pomace was procured from a juice-making plant (Mungyeong-si, Gyeongsangbukdo, Korea), sun-dried for 24 to $48 \mathrm{~h}$ and stored at $4^{\circ} \mathrm{C}$ until use. The fruit pomace was then fermented using an indigenous isolate, Wickerhamomyces sp. SK1819 (1\%, v/v) in yeast malt broth (Difco Laboratories, Detroit, MI, USA) at 1:1 ratio at $30^{\circ} \mathrm{C}$ and $100 \mathrm{rpm}$ for $16 \mathrm{~h}$. The fresh pine needles (Pinus densiflora) were collected from the region of Bonghwa-gun, Gyeongsangbuk-do, Korea. The needles were then washed, air-dried, and spontaneously fermented in a medium containing equal amounts of water and sugar for a period of 1 year. The supernatant of this spontaneously fermented pine needles was used as a fermented pine needle extract. The Chinese chive was purchased from a local market (Seoul, Korea) and juice was squeezed using a juicer (Angel-juicer, Busan, Korea). Chinese chive powder was prepared by mixing its juice with soybean meal (used as excipient) in the ratio of 7:3 and dried at $40^{\circ} \mathrm{C}$ for $36 \mathrm{~h}$ in a dry oven (WFO-600S, Eyela Singapore Pte. Ltd., Singapore). Table 1 presents the proximate chemical composition of the tested SPA, including moisture, crude protein, crude fat, crude fiber, ash, calcium, and available phosphorus [27].

\section{Experimental animal and design}

A total of 135 Hy-line brown laying hens was randomly assigned to 3 treatment groups with 5 replicates of 9 birds each. The experimental house was a 2 -tier battery-cage facility and hens were housed 3 per cage of the dimension of $43 \mathrm{~cm}$ length, $45 \mathrm{~cm}$ deep, and $42 \mathrm{~cm}$ height. A corn-soybean meal basal diet was formulated to meet or exceed the 1994 National Research Council recommendations [28] (Table 2). The levels of SPA supplied to the basal diet was as follows: $0 \%, 0.1 \%$, and $0.3 \%$. The appropriate amount of SPA was added to the basal diet and mixed for 5 min using a feed mixer (DKM-

Table 1. Proximate chemical composition of the tested SPA

\begin{tabular}{lc}
\hline Item & Amount $\mathbf{( g / 1 0 0 ~ g ) ~}$ \\
\hline Moisture & 52.49 \\
Crude protein & 10.15 \\
Crude fat & 7.88 \\
Crude fiber & 7.56 \\
Ash & 1.74 \\
Calcium & 0.08 \\
Available phosphorus & 0.16 \\
\hline
\end{tabular}

SPA, fermented S. chinensis fruit pomace, fermented pine needle extract, and Chinese chive powder in the ratio of 2:2:1. 
Table 2. Ingredients and chemical compositions of the basal diet

\begin{tabular}{|c|c|}
\hline Items & Amount \\
\hline \multicolumn{2}{|l|}{ Ingredients (\%) } \\
\hline Corn & 50.00 \\
\hline Corn dried distillers' grains with solubles (DDGS) & 21.24 \\
\hline Limestone & 10.20 \\
\hline Soybean meal & 7.42 \\
\hline Rapeseed meal & 5.00 \\
\hline Sesame seed oil meal & 2.00 \\
\hline Feather meal & 1.50 \\
\hline Tallow & 0.90 \\
\hline Mono dicalcium phospate (MDCP) & 0.59 \\
\hline Syn. Lys-sulfate & 0.38 \\
\hline Syn. Met (liq.) & 0.11 \\
\hline Syn. Thr & 0.03 \\
\hline Salt & 0.20 \\
\hline Mineral premix ${ }^{1)}$ & 0.18 \\
\hline Vitamin premix ${ }^{2)}$ & 0.11 \\
\hline Sodium bicarbonate & 0.10 \\
\hline Choline-chloride (50\%) & 0.05 \\
\hline \multicolumn{2}{|l|}{ Calculated values } \\
\hline TMEn (kcal/kg) & 2,800 \\
\hline Crude protein (\%) & 17.00 \\
\hline Crude fat (\%) & 5.30 \\
\hline Crude fiber (\%) & 3.70 \\
\hline $\mathrm{Ca}(\%)$ & 4.00 \\
\hline Lys (\%) & 0.83 \\
\hline TSAA (\%) & 0.72 \\
\hline Available P (\%) & 0.27 \\
\hline \multicolumn{2}{|c|}{$\begin{array}{l}\text { TMEn, true metabolizable energy; TSAA, total sulphur amino acid. } \\
\text { 1) Mineral premix: provide followings per kg of diet: Fe, } 30 \text { mg; } Z n, 25 \text { mg; } \\
\text { Mn, } 20 \text { mg; } C u, 5 \text { mg; Co, } 0.15 \text { mg; Se, } 0.1 \text { mg. } \\
\text { 2) Vitamin premix: provide followings per kg of diet: vitamin } A, 40,000 \text { IU; } \\
\text { vitamin } D_{3}, 8,000 \text { IU; vitamin } E, 10 \mathrm{IU} \text {; nicotinic, } 60 \text { mg; pantothenic acid, } \\
20 \text { mg; vitamin } B_{1}, 4 \text { mg; vitamin } B_{2}, 12 \text { mg; vitamin } B_{6}, 6 \text { mg; vitamin } K_{3}, 4 \\
\text { mg; folic acid, } 2 \text { mg; vitamin } B_{12}, 0.02 \text { mg. }\end{array}$} \\
\hline
\end{tabular}

350SU, Daekwang Co., Ltd., Hwaseong, Gyeonggi-do, Korea) to obtain a homogeneous mixture. The feeding experiment was performed for $6 \mathrm{wk}$ after 2 -wk of adaptation period. During the entire experimental period, ad libitum feed in mash form and water were provided with $16 \mathrm{~h}$ light and $8 \mathrm{~h}$ of a dark period.

This experiment was performed in accordance with the Animal Care and Use Committee (KU18129) of Konkuk University (Seoul, Korea) in November 2014.

\section{Egg productivity}

The number of eggs produced was recorded daily at 13:00 $\mathrm{h}$ including those were broken. Egg production rate (\%) was calculated from the total number of eggs laid in $1 \mathrm{wk}$ divided by the total number of hen days in that week on a replicate basis. Average egg weight was obtained by dividing the total weight of collected eggs by the number of normal eggs. The daily egg mass was calculated by multiplying the egg production rate by the average egg weight. We recorded feed intake weekly for each replicate. The feed conversion ratio (FCR) was calculated as grams of feed intake per gram of daily egg mass produced.

\section{Egg quality}

On a weekly basis, fifteen eggs per treatment (3 eggs per replicate) were randomly collected for the egg quality measurements including egg weight, egg breaking strength, Haugh unit (HU), eggshell color, yolk color, and eggshell thickness. The egg breaking strength was measured using egg breaking strength tester (FHK, Fujihira Co. Ltd., Tokyo, Japan). $\mathrm{HU}$, a measure of the height of the albumen of the eggs broken out on a flat surface, was calculated using the formula $100 \times \log (\mathrm{H}+7.57-1.7 \mathrm{~W} 0.37)$, where $\mathrm{H}$ is the height of the egg white $(\mathrm{mm})$ and $\mathrm{W}$ is the weight of the egg $(\mathrm{g})$. Egg shell color was measured using an eggshell color fan (Samyang Co., Ltd., Seoul, Korea). Egg yolk color was measured using an egg yolk color fan of Roche. Egg shell thickness was measured at central part of the eggshell fragments without eggshell membrane using a Digimatic micrometer (Series 293-330-30, Mitutoyo Corporation, Kawasaki, Japan).

\section{Egg storage}

Four days before the end of the experiment, all the normal eggs were collected to measure the $\mathrm{HU}$ according to the storage period of the eggs. Collected eggs were stored at $18^{\circ} \mathrm{C}$ for $4 \mathrm{wk}$, and a total of 45 eggs, 3 eggs with similar egg weight per replicate, were selected at 1,2 , and 4 wk to measure the $\mathrm{HU}$ as described above.

\section{Blood parameters}

After 6 wk of feeding, 8 hens were selected from each treatment with a standard weight of $2.1 \pm 0.1 \mathrm{~kg}$ to measure the blood parameters. About $10 \mathrm{~mL}$ of blood was collected from the carotid artery and serum was separated by centrifugation at $1,500 \mathrm{rpm}$ for $20 \mathrm{~min}$. The separated serum was sent to Seoul Clinical Laboratories (Giheung-gu, Yongin-si, Gyeonggido, Korea) to analyze the levels of aspartate aminotransferase (AST), alanine aminotransferase (ALT), triglyceride (TG), total cholesterol (TC), albumin, globulin, creatinine, calcium, phosphate, amylase. The analysis was performed with an automated analyzer (Hitachi 7600, Tokyo, Japan). Highdensity lipoprotein (HDL) cholesterol was measured using an HDL diagnostic kit (HDL-cholesterol kit, Youngdong Medical Corporation, Seoul, Korea). Afterthat, low-density lipoprotein (LDL) and very-low-density lipoprotein (VLDL) cholesterol were precipitated by adding sedimentation reagent (dextran sulfate, phosphotungstic acid) to the serum and the remaining ester-type cholesterol was decomposed with esterase and released. Subsequently, an enzyme solution (cholesterol oxidase, peroxidase) was added to form a red quinoid pigment, and the absorbance was measured at 
$500 \mathrm{~nm}$. HDL (\%) represents the percentage of HDL in TC content, and LDL+VLDL value was calculated by subtracting HDL from TC.

\section{IgA, IgG, and IgM contents in the blood}

Blood immunoglobin (Ig) including IgA, IgG, IgM content was measured using the Chicken IgA, IgG, and IgM ELISA Kit (Bethyl Laboratories, Inc., Montgomery, TX, USA). The prepared samples and standards were placed in a chicken IgA pre-coated 96-well plate $100 \mu \mathrm{L}$ each and left at room temperature for $1 \mathrm{~h}$. It was then washed four times with a wash solution (50 mM Tris, $0.14 \mathrm{M} \mathrm{NaCl}$, and $0.05 \%(\mathrm{v} / \mathrm{v})$ tween 20). Then, $100 \mu \mathrm{L}$ of chicken IgA, IgG, and IgM detection antibodies were added to each well, and then reacted at room temperature for $1 \mathrm{~h}$, and washed again four times using a washing solution. Subsequently, $100 \mu \mathrm{L}$ of antibody Avidinhorseradish peroxidase conjugated solution was added to each well, followed by reaction for $30 \mathrm{~min}$, and then washed four times. Then, $100 \mu \mathrm{L}$ of tetramethylbenzidine substrate solution was added to each well, and color change was observed for $30 \mathrm{~min}$ in the dark. Finally, the reaction was stopped by adding $100 \mu \mathrm{L}$ of stop solution $\left(2 \mathrm{M}, \mathrm{H}_{2} \mathrm{SO}_{4}\right)$ to each well, then absorbance was measured at $450 \mathrm{~nm}$ using a microplate reader (Benchma plus, Bio-Rad Laboratories, Hercules, CA, USA). Standard curves were used to calculate the content of IgA, IgG, and IgM in blood.

\section{Visceral organ properties}

After collecting blood, liver, spleen, gizzard, heart, abdominal fat, jejunum, ileum, cecum and ovary were collected and expressed in terms of relative weight per $100 \mathrm{~g}$ of body weight. The length of jejunum and ileum were measured after removing the mesentery and expressed as relative length per $100 \mathrm{~g}$ of body weight. After that, the contents of jejunum and ileum were collected, and the $\mathrm{pH}$ of the contents was measured using a digital pH meter (735P, iStek Inc., Seoul, Korea).

\section{Statistical analysis}

Data are analyzed in a completely randomized design using the PROC mixed procedure of SAS version 9.4 (SAS Institute, Cary, NC, USA). The data of productivity performance and egg quality were analyzed by considering replicate as the experimental unit. For the measurements of blood and organ properties, individual bird was considered as the experimental unit. The significance of difference among the treatments was assessed using the Tukey's test. Means were considered statistically different at $\mathrm{p}$-value $<0.05$. Results were presented as least squares means \pm standard error.

\section{RESULTS}

\section{Effect on laying performance}

The effects of dietary supplementation of SPA on laying performance in hens from 50 to $56 \mathrm{wk}$ of age are shown in Table 3. During this period, the SPA supplementation into layers' diet had no effects on egg production, egg weight, feed conversion, and egg mass when compared to the control group $(p>0.05)$. However, a linear significant increase in the feed intake was observed with the increase in SPA levels $(\mathrm{p}=$ $0.03)$.

\section{Effect on egg quality}

The effects of dietary supplementation of SPA in laying hens on HU, eggshell color, egg yolk color, eggshell breaking strength and eggshell thickness are shown in Table 4. Dietary treatments had a significant effect $(\mathrm{p}<0.05)$ on HU. The SPA $(0.3 \%)$ group had higher $\mathrm{HU}$ as compared with control and SPA $(0.1 \%)$ groups $(p=0.001)$. However, dietary supplementation of SPA had no effects on eggshell color, egg yolk color, eggshell breaking strength, and eggshell thickness $(\mathrm{p}>0.05)$.

\section{Haugh unit change according to egg storage period The effect of dietary supplementation of SPA in laying hens on $\mathrm{HU}$ according to egg storage period is shown in Figure 1. During storage, the HU decreased in the case of all the di- etary treatments. However, the supplementation of SPA had no effects on $\mathrm{HU}$ of eggs stored for $4 \mathrm{wk}$ at $18^{\circ} \mathrm{C}(\mathrm{p}>0.05)$.}

Table 3. Effect of supplementary SPA on productivity in laying hens

\begin{tabular}{|c|c|c|c|c|}
\hline \multirow{2}{*}{ Item } & \multicolumn{3}{|c|}{ Treatments $^{1)}$} & \multirow{2}{*}{ p-value } \\
\hline & CON & SPA $(0.1 \%)$ & SPA $(0.3 \%)$ & \\
\hline Egg production (\%) & $81.25 \pm 6.94$ & $89.62 \pm 1.21$ & $84.09 \pm 7.02$ & 0.10 \\
\hline Egg weight (g) & $64.37 \pm 1.54$ & $64.12 \pm 0.45$ & $64.34 \pm 0.94$ & 0.92 \\
\hline Egg mass (g/hen/d) & $52.31 \pm 5.10$ & $57.46 \pm 0.89$ & $54.11 \pm 4.41$ & 0.15 \\
\hline Feed intake (g/hen/d) & $121.86 \pm 1.64^{b}$ & $123.63 \pm 1.14^{\mathrm{ab}}$ & $124.08 \pm 0.68^{a}$ & 0.03 \\
\hline FCR (g feed/g egg) & $2.39 \pm 0.23$ & $2.18 \pm 0.04$ & $2.36 \pm 0.21$ & 0.19 \\
\hline
\end{tabular}

Values are means \pm standard error.

SPA, fermented $S$. chinensis fruit pomace, fermented pine needle extract, and Chinese chive powder in the ratio of 2:2:1; FCR, feed conversion ratio.

1) CON, control, basal diet; SPA (0.1\%), basal diet+0.1\% SPA; SPA (0.3\%), basal diet $+0.3 \%$ SPA.

$a, b$ Means within a same row with different letters differ significantly at $p<0.05$. 
Table 4. Effect of supplementary SPA on egg quality in laying hens

\begin{tabular}{lcccc}
\hline \multirow{2}{*}{ Item } & \multicolumn{3}{c}{ Treatments $^{\mathbf{1})}$} & P-value \\
\cline { 2 - 4 } & CON & SPA (0.1\%) & SPA (0.3\%) & 0.001 \\
Haugh units & $89.65 \pm 8.94^{\text {ab }}$ & $87.12 \pm 10.58^{\mathrm{b}}$ & $92.20 \pm 8.04^{\mathrm{a}}$ & 0.26 \\
Egg yolk color & $7.93 \pm 0.56$ & $8.07 \pm 0.60$ & $7.96 \pm 0.60$ & 0.68 \\
Eggshell color & $11.68 \pm 1.46$ & $11.70 \pm 1.38$ & $11.84 \pm 1.34$ & 0.07 \\
Eggshell breaking strength $\left(\mathrm{kg} / \mathrm{cm}^{2}\right)$ & $2.91 \pm 0.81$ & $3.18 \pm 0.78$ & $2.98 \pm 0.85$ & 0.39 \\
Eggshell thickness $(\mathrm{mm})$ & $0.41 \pm 0.04$ & $0.41 \pm 0.05$ & $0.81 \pm 3.86$ & \\
\hline
\end{tabular}

Values are means \pm standard error.

SPA, fermented $S$. chinensis fruit pomace, fermented pine needle extract, and Chinese chive powder in the ratio of 2:2:1.

1) CON, control, basal diet; SPA (0.1\%), basal diet $+0.1 \%$ SPA; SPA $(0.3 \%)$, basal diet+0.3\% SPA.

${ }^{a, b}$ Means within a same row with different letters differ significantly at $p<0.05$.

\section{Impact on blood parameters}

The effects of SPA inclusion in diets on blood biochemical parameters of layers at the end of the experiment (56 wk of age) are presented on Table 5. Serum levels of AST, ALT, TG, TC, HDL, HDL (\%) LDL+VLDL, albumin, globulin, creatinine, calcium, and amylase did not differ among the dietary treatments $(\mathrm{p}>0.05)$. However, blood phosphate content was significantly higher in SPA supplemented groups than the control group $(\mathrm{p}=0.02)$.

\section{Effect on immune markers in the blood}

Table 6 shows the effects of dietary supplementation of SPA on laying hens on the Ig content in the blood. Ig including IgA, IgG, and IgM did not differ significantly in all the treatments $(\mathrm{p}>0.05)$.

\section{Impact on visceral organs properties}

A summary of visceral organ weights of the experimental birds is shown in Table 7. After 6 wk of dietary SPA supple- mentation, there were no statistically significant changes in the relative weights of liver, spleen, heart, gastrointestinal tracts (gizzard, jejunum, ileum, and cecum), and abdominal fat in comparison to the control birds ( $p>0.05$ ). The relative weight of the liver, however, was reduced $(p=0.09)$ in the supplemented treatment groups as compared with that of the control group. The $\mathrm{pH}$ and length of the jejunum and cecum remained unaffected among the dietary treatments ( $\mathrm{p}>0.05)$ (Table 8).

\section{DISCUSSION}

Several studies have supported the nutritional value of plant extracts as natural feed additives in layer diets [3-5,8]. In this study, egg production, egg weight, egg mass, and FCR were not affected with or without dietary supplementation of SPA, suggesting that there was no toxicity of the phytogenic used up to the level of $0.3 \mathrm{~g} / \mathrm{kg}$ of diet. The absence of adverse effects on performance traits has also been reported in broiler

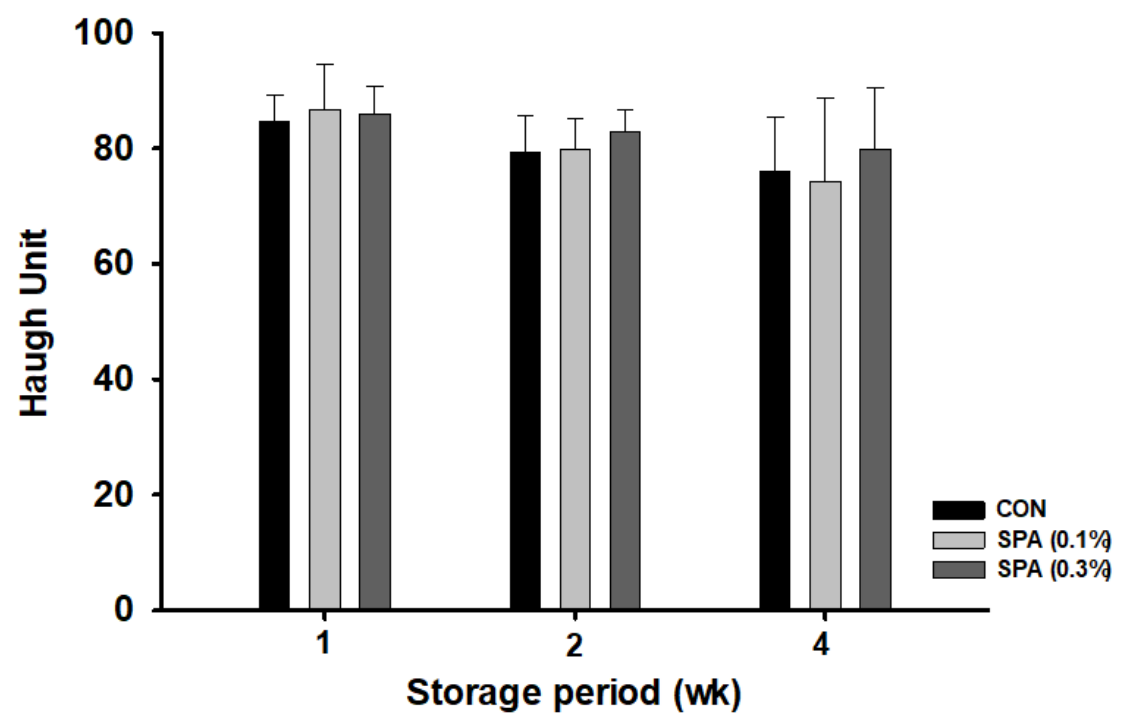

Figure 1. Effect of supplementary SPA on change in Haugh unit during egg storage of $28 \mathrm{~d}$ at $18^{\circ} \mathrm{C}$. Values are presented as means \pm standard error. SPA, fermented S. chinensis fruit pomace, fermented pine needle extract, and Chinese chive powder in the ratio of 2:2:1. CON, control; basal diet; SPA (0.1\%), basal diet+0.1\% SPA; SPA (0.3\%), basal diet+0.3\% SPA. 
Table 5. Effect of supplementary SPA on blood characteristics in laying hens

\begin{tabular}{|c|c|c|c|c|}
\hline \multirow{2}{*}{ Item } & \multicolumn{3}{|c|}{ Treatments ${ }^{1)}$} & \multirow{2}{*}{ p-value } \\
\hline & CON & SPA $(0.1 \%)$ & SPA $(0.3 \%)$ & \\
\hline AST (U/L) & $150.00 \pm 7.39$ & $151.75 \pm 9.74$ & $162.40 \pm 11.26$ & 0.17 \\
\hline $\mathrm{ALT}(\mathrm{U} / \mathrm{L})$ & $4.38 \pm 1.06$ & $3.75 \pm 1.04$ & $4.00 \pm 0.93$ & 0.47 \\
\hline $\mathrm{TG}(\mathrm{mg} / \mathrm{dL})$ & $1,159.67 \pm 166.16$ & $892.00 \pm 53.74$ & $1,026.40 \pm 78.72$ & 0.08 \\
\hline $\mathrm{TC}(\mathrm{mg} / \mathrm{dL})$ & $116.67 \pm 20.65$ & $107.29 \pm 19.35$ & $116.00 \pm 6.96$ & 0.56 \\
\hline $\mathrm{HDL}(\mathrm{mg} / \mathrm{dL})$ & $11.58 \pm 3.56$ & $13.75 \pm 6.45$ & $11.08 \pm 0.74$ & 0.57 \\
\hline HDL (\%) & $9.15 \pm 1.59$ & $12.04 \pm 4.70$ & $9.56 \pm 0.53$ & 0.36 \\
\hline $\mathrm{LDL}+\mathrm{VLDL}(\mathrm{mg} / \mathrm{dL})$ & $105.09 \pm 17.14$ & $98.26 \pm 13.36$ & $104.92 \pm 6.54$ & 0.58 \\
\hline Albumin (g/dL) & $2.70 \pm 0.19$ & $2.66 \pm 0.23$ & $2.6 \pm 0.23$ & 0.77 \\
\hline Globulin (g/dL) & $7.54 \pm 10.11$ & $2.72 \pm 0.28$ & $2.84 \pm 0.49$ & 0.36 \\
\hline Creatinine (mg/dL) & $0.26 \pm 0.08$ & $0.28 \pm 0.06$ & $0.25 \pm 0.09$ & 0.84 \\
\hline Calcium (mg/dL) & $20.48 \pm 2.17$ & $21.56 \pm 1.60$ & $20.60 \pm 1.59$ & 0.60 \\
\hline Phosphate (mg/dL) & $5.24 \pm 0.81^{b}$ & $6.96 \pm 0.68^{a}$ & $6.26 \pm 0.94^{\mathrm{ab}}$ & 0.02 \\
\hline Amylase (U/L) & $287.20 \pm 61.37$ & $291.6 \pm 9.89$ & $270.92 \pm 51.92$ & 0.77 \\
\hline
\end{tabular}

Values are means \pm standard error.

SPA, fermented $S$. chinensis fruit pomace, fermented pine needle extract, and Chinese chive powder in the ratio of 2:2:1; AST, aspartate aminotransferase; ALT, alanine aminotransferase; TG, triglyceride; TC, total cholesterol; HDL, high-density lipoprotein; LDL, low-density lipoprotein; VLDL, very-low-density lipoprotein.

1) CON, control, basal diet; SPA (0.1\%), basal diet+0.1\% SPA; SPA (0.3\%), basal diet+0.3\% SPA.

$a, b$ Means within a same row with different letters differ significantly at $p<0.05$.

breeds when fed with pine (Pinus brutia) needle powder $(10 \mathrm{~g} / \mathrm{kg}$ of diet) [18] and S. chinensis powder $(5,10$, or 20 $\mathrm{g} / \mathrm{kg}$ of diet) [13]. Alternatively, Kim et al [29] observed that the egg production rate was significantly improved when the mixtures of Artemisia campestris (A. campestris), $\mathrm{Ca}$ mellia sinensis (C. sinensis), S. chinensis, and Viscum album

Table 6. Effect of supplementary SPA on immunoglobulins in laying hens

\begin{tabular}{lcccc}
\hline \multirow{2}{*}{ Item } & \multicolumn{3}{c}{ Treatments $^{\mathbf{1})}$} & \multirow{2}{*}{ p-value } \\
\cline { 2 - 4 } & CON & SPA (0.1\%) & SPA (0.3\%) & \\
\hline IgA & $189.18 \pm 7.46$ & $190.46 \pm 13.75$ & $190.31 \pm 10.68$ & 0.98 \\
IgG & $37.33 \pm 14.62$ & $33.79 \pm 14.19$ & $29.77 \pm 14.34$ & 0.67 \\
IgM & $35.96 \pm 5.19$ & $46.19 \pm 8.82$ & $45.69 \pm 14.31$ & 0.18 \\
\hline
\end{tabular}

Values are means \pm standard error.

SPA, fermented $S$. chinensis fruit pomace, fermented pine needle extract, and Chinese chive powder in the ratio of 2:2:1; Ig, immunoglobulin.

1) CON, control, basal diet; SPA (0.1\%), basal diet+0.1\% SPA; SPA (0.3\%), basal diet+0.3\% SPA. var. coloratum were fed to laying hens. Similarly, Ma et al [30] observed the beneficial effects of the S. chinensis on the

Table 7. Effect of supplementary SPA on relative weights of organs in laying hens

\begin{tabular}{lcccc}
\hline \multirow{2}{*}{ Item } & \multicolumn{3}{c}{ Treatments $^{\mathbf{1})}$} & p-value \\
\cline { 2 - 5 } & $\mathbf{C O N}$ & SPA (0.1\%) & SPA (0.3\%) & \\
\hline Liver & $1.68 \pm 0.28$ & $1.55 \pm 0.17$ & $1.42 \pm 0.23$ & 0.09 \\
Spleen & $0.10 \pm 0.02$ & $0.09 \pm 0.02$ & $0.10 \pm 0.02$ & 0.94 \\
Heart & $0.43 \pm 0.08$ & $0.42 \pm 0.06$ & $0.45 \pm 0.06$ & 0.61 \\
Gizzard & $1.52 \pm 0.12$ & $1.61 \pm 0.22$ & $1.59 \pm 0.10$ & 0.46 \\
Jejunum & $0.71 \pm 0.13$ & $0.61 \pm 0.17$ & $0.66 \pm 0.10$ & 0.37 \\
Ileum & $0.58 \pm 0.13$ & $0.56 \pm 0.11$ & $0.51 \pm 0.09$ & 0.46 \\
Cecum & $0.29 \pm 0.05$ & $0.27 \pm 0.04$ & $0.27 \pm 0.06$ & 0.70 \\
Abdominal fat & $4.63 \pm 1.26$ & $3.77 \pm 1.09$ & $4.35 \pm 0.84$ & 0.29 \\
\hline
\end{tabular}

Values are means \pm standard error.

SPA, fermented $S$. chinensis fruit pomace, fermented pine needle extract, and Chinese chive powder in the ratio of 2:2:1.

1) CON, control, basal diet; SPA (0.1\%), basal diet+0.1\% SPA; SPA (0.3\%), basal diet+0.3\% SPA.

Table 8. Effect of supplementary SPA on the length and pH of ileum and jejunum in laying hens

\begin{tabular}{|c|c|c|c|c|}
\hline \multirow{2}{*}{ Item } & \multicolumn{3}{|c|}{ Treatments $^{1)}$} & \multirow{2}{*}{ p-value } \\
\hline & CON & SPA $(0.1 \%)$ & SPA $(0.3 \%)$ & \\
\hline Jejunum pH & $5.90 \pm 0.17$ & $6.08 \pm 0.27$ & $5.99 \pm 0.15$ & 0.25 \\
\hline Ileum pH & $6.61 \pm 0.39$ & $6.56 \pm 0.50$ & $6.24 \pm 0.28$ & 0.16 \\
\hline Jejunum length (cm) & $69.44 \pm 3.70$ & $62.38 \pm 5.18$ & $65.25 \pm 8.12$ & 0.08 \\
\hline Jejunum length/100 g BW & $3.34 \pm 0.23$ & $3.04 \pm 0.30$ & $3.23 \pm 0.46$ & 0.23 \\
\hline Ileum length (cm) & $62.44 \pm 5.90$ & $61.88 \pm 5.08$ & $60.63 \pm 5.76$ & 0.80 \\
\hline Ileum length/100 g BW & $3.00 \pm 0.30$ & $3.02 \pm 0.30$ & $3.00 \pm 0.30$ & 0.99 \\
\hline
\end{tabular}

Values are means \pm standard error.

SPA, fermented $S$. chinensis fruit pomace, fermented pine needle extract, and Chinese chive powder in the ratio of 2:2:1; BW, body weight.

${ }^{1)}$ CON, control, basal diet; SPA (0.1\%), basal diet $+0.1 \%$ SPA; SPA $(0.3 \%)$, basal diet+0.3\% SPA. 
egg production traits of laying hens during heat stress. The inconsistencies in these results could be related to the variation in animal breeds and their health status, dose of herbs, and bioactive constituents in the used plant extracts as well as the experimental conditions. In a concentration-dependent manner, the SPA used in this study improved the feed intake. It is assumed that SPA might have improved the palatability of feed due to their aromatic characteristics and thereby could promote feed consumption when added to layers' diets. This result was consistent with previous reports those indicated increased feed intake in broilers fed pine (Pinus yunnanensis) needle powder at $50 \mathrm{~g} / \mathrm{kg}$ diet [19] and onion (Allium cepa) powder at $30 \mathrm{~g} / \mathrm{kg}$ diet [31]. Due to the non-availability of the information related to layers, the productive performance results of this study were also compared with the research that examined the supplemental effects of some PFA on the growth performance of broilers.

This study showed no significant difference in yolk color and eggshell properties (color, breaking strength, and thickness) among the dietary treatments. This is consistent with the previous reports that indicated no alteration in most of the egg quality traits in laying hens fed S. chinensis [32] and pine needles [33]. Li et al [32] reported that egg weight, eggshell thickness, egg white height, $\mathrm{HU}$, and eggshell breaking strength had not changed in a study that fed 24-wk-old Lohmann Brown laying hens with $0.5 \%$ to $1 \%$ Chinese herbal mixture (containing 70\% pine needles and 30\% Artemisia annua) in the diet. Kim and Paik [33] also indicated no changes in eggshell strength, eggshell thickness, eggshell color, egg yolk, and HU when 66-wk-old Hy-line Brown hens were fed $0.2 \%$ plant extracts, including turmeric, Angelica gigas, S. chinensis, Glycyrrhiza glabra, and Levisticum officinale. On the other hand, Kim et al [29] demonstrated that HU and egg yolk color were significantly increased compared to control, but eggshell thickness, and eggshell breaking strength were not changed when a mixture of A. campestris, C. sinensis, S. chinensis, and Viscum album var. coloratum was fed to laying hens. The discrepancies in the results of egg quality may be ascribed to the variability in animal breed, age, dosage, and environmental conditions. The literature relating Chinese chive supplementation to layers is scarce. $\mathrm{HU}$ is the "gold standard" of internal egg quality determination. Eggs are graded based on their HU values: AA, 72 or more; A, 71 to 60; and B, <60 [34]. Herein, HU in all the dietary treatments were above 72 , suggesting that the eggs produced in this study are of good quality. Moreover, the inclusion of SPA at $3 \mathrm{~g} / \mathrm{kg}$ of diet in laying hen diets significantly increased HU. These improvements in HU may be attributed to the antioxidant property of bioactive constituents in S. chinensis, pine needles and Chinese chive. In particular, the antioxidant properties of these plant extracts have been reported in previous studies [14,18,23], which might have reduced the lipid and protein oxidation in eggs. In addition, the bio-active constituents of plants were shown to protect magnum and uterus, as well as enhance the albumen secretion in laying birds [35], however, this needs to be specifically studied. HU also acts an important indicator of egg freshness and it is related to shelf life [36]. In the current study, HU decreased with the storage time as expected, but the effect of dietary SPA inclusion was not observed in the HU of eggs during storage.

Blood biochemical constituents can be indicative of the health status of birds. In the current study, except serum phosphate levels, no changes in blood biochemistry were observed. Phosphorus is an essential nutrient for laying hens, which plays an important role in bone formation and maintenance, energy storage, cytoskeletal maintenance, and egg production [37]. The use of exogeneous phytase to improve the phosphorus availability and blood phosphorus content of monogastric animals has been shown to be an ideal approach and is actively studied $[37,38]$. However, few studies have been conducted on the effects of dietary plant extracts supplementation on the blood phosphorus content in laying hens. The dietary SPA used in this study resulted in an increase in serum phosphate, which might be caused due to the increased digestibility of phosphorus or due to the presence of higher amount of available phosphorus in SPA supplemented diets. The previous reports of Amad et al [39] and Hafeez et al [40] observed the improvement in the ileal digestibility of nutrients including phosphorus in broilers by a dietary PFA and attributed it to the stimulation of endogenous digestive enzymes and to an increased absorption surface area in the intestine.

The changes in size and structure of internal organs are important for predicting the effect of diet and its components on the development and function of organs in laying hens. Generally, as the size of the organ increases, the energy required to maintain the organ increases, which in turn decreases the amount of energy input to productivity [4]. Our results revealed that dietary SPA supplementation did not affect relative weights of internal organs (liver, spleen, heart, gizzard, jejunum, and cecum), intestinal length, intestine $\mathrm{pH}$, and abdominal fat, which indicated that dietary supplementation with SPA up to $3 \mathrm{~g} / \mathrm{kg}$ of diet could have no observed adverse effects on organ development. Research on the effects of supplementing PFA in layer diets on internal organ characteristics are limited.

Ig content plays an essential role in immune regulation. Three main classes of Ig exist in poultry: IgA, IgM, and IgY. IgY is a counterpart of mammalian IgG [41]. It has been thought that the antioxidant constituents of $S$. chinensis, pine needles, and Chinese chive might have a role in the development of immune response in birds. In this study, dietary treatments did not affect serum IgA, IgM, and IgG contents, 
suggesting no effects of SPA on humoral immune status of laying hens. In contrast, Ma et al [30] indicated that supplementation with $S$. chinensis at $10 \mathrm{~g} / \mathrm{kg}$ of diet significantly elevated antibody responses against Newcastle disease virus in laying hens during heat stress. These inconsistent results could be explained by the fact that healthy poultry reared under clean and ideal environmental conditions usually do not respond to the feed additives [42]. Another explanation could be the higher dosage of SPA may be needed to stimulate humoral immune responses. Further studies need to be conducted in laying hens under stress conditions to evaluate the effects of SPA on immune responses.

In conclusion, dietary supplementation of SPA containing a mixture of fermented S. chinensis pomace, fermented pine needle extract, and Chinese chive powder, positively influenced feed intake, HU, and blood phosphorus in laying hens. However, most of the productivity and egg quality traits remained unaffected by SPA inclusion in layers' diets. Moreover, no adverse effects on blood and organ characteristics were observed. Further research is required to assess the SPA effects on immune response indices under stress or pathogenic challenge conditions.

\section{CONFLICT OF INTEREST}

We certify that there is no conflict of interest with any financial organization regarding the material discussed in the manuscript.

\section{ACKNOWLEDGMENTS}

This study was supported by Korea Institute of Planning and Evaluation for Technology in Food, Agriculture, Forestry (IPET) through Agri-Bio Industry Technology Development Program, funded by Ministry of Agriculture, Food and Rural Affairs (MAFRA) (118051-03), Seoul, Korea.

\section{REFERENCES}

1. Scott AM, Beller E, Glasziou P, et al. Is antimicrobial administration to food animals a direct threat to human health? A rapid systematic review. Int J Antimicrob Agents 2018;52: 316-23. https://doi.org/10.1016/j.ijantimicag.2018.04.005

2. Suresh G, Das RK, Kaur Brar S, et al. Alternatives to antibiotics in poultry feed: molecular perspectives. Crit Rev Microbiol 2018;44:318-35. https://doi.org/10.1080/1040841X.2017. 1373062

3. Abdel-Wareth AAA, Lohakare JD. Productive performance, egg quality, nutrients digestibility, and physiological response of bovans brown hens fed various dietary inclusion levels of peppermint oil. Anim Feed Sci Technol 2020;267:114554. https://doi.org/10.1016/j.anifeedsci.2020.114554
4. Marume U, Mokagane JM, Shole CO, Hugo A. Citrullus lanatus essential oils inclusion in diets elicit nutraceutical effects on egg production, egg quality, and physiological characteristics in layer hens. Poult Sci 2020;99:3038-46. https:// doi.org/10.1016/j.psj.2020.01.029

5. dos Santos AFA, Da Silva AS, Galli GM, et al. Addition of yellow strawberry guava leaf extract in the diet of laying hens had antimicrobial and antioxidant effect capable of improving egg quality. Biocatal Agric Biotechnol 2020;29:101788. https:// doi.org/10.1016/j.bcab.2020.101788

6. Ayaşan T. Effects of dietary inclusion of protexin (probiotic) on hatchability of Japanese quails. Indian J Anim Sci 2013; 83:78-81.

7. Windisch W, Schedle K, Plitzner C, Kroismayr A. Use of phytogenic products as feed additives for swine and poultry. J Anim Sci 2008;86(Suppl 14):E140-8. https://doi.org/10.2527/ jas.2007-0459

8. Liu M, Lu Y, Gao P, et al. Effect of curcumin on laying performance, egg quality, endocrine hormones, and immune activity in heat-stressed hens. Poult Sci 2020;99:2196-202. https:// doi.org/10.1016/j.psj.2019.12.001

9. Sevim B, Cufadar Y. Effects of an addition of different essential oils and their combinations to diets on performance and carcass characteristics parameters in broilers. Turk J Agric Food Sci Technol 2017;5:964-8. https://doi.org/10.24925/ turjaf.v5i8.964-968.1261

10.Panossian A, Wikman G. Pharmacology of Schisandra chinensis Bail.: an overview of Russian research and uses in medicine. J Ethnopharmacol 2008;118:183-212. https://doi.org/10.1016/ j.jep.2008.04.020

11.Gnabre J, Unlu I, Chang TC, et al. Isolation of lignans from Schisandra chinensis with anti-proliferative activity in human colorectal carcinoma: structure-activity relationships. J Chromatogr B 2010;878:2693-700. https://doi.org/10.1016/ j.jchromb.2010.08.005

12. Chen X, Zhang Y, Zu Y, Fu Y, Wang W. Composition and biological activities of the essential oil from Schisandra chinensis obtained by solvent-free microwave extraction. LWT Food Sci Technol 2011;44:2047-52. https://doi.org/10.1016/j.lwt. 2011.05.013

13. Kim YJ, Chung TH, Choi IH. Influence of supplemental Schisandra chinensis powder on growth performance, serum cholesterol, and meat quality of broilers. Acta Agric Scand A Anim Sci 2013;63:175-82. https://doi.org/10.1080/090647 02.2013.861861

14. Ko YH, Moon YS, Sohn SH, Jung CY, Jang I. Effect of dietary supplementation of plum or omija on growth performance, blood biochemical profiles and antioxidant defense system in broiler chickens. Korean J Poult Sci 2012;39:121-31. https:// doi.org/10.5536/KJPS.2012.39.2.121

15.Kwak CS, Moon SC, Lee MS. Antioxidant, antimutagenic, and antitumor effects of pine needles (Pinus densiflora). 
Nutr Cancer 2006;56:162-71. https://doi.org/10.1207/s153 27914nc5602_7

16. Kim YJ, Kim CM, Choi JH, Choi IH. Effect of dietary mugwort (Artemisia vulgaris L.) and pine needle powder (Pinus densiflora) on growth performance, serum cholesterol levels, and meat quality in broilers. Afr J Biotechnol 2012;11:11866-73. https://doi.org/10.5897/AJB11.3782

17.Zeng WC, Zhang Z, Gao H, Jia LR, He Q. Chemical composition, antioxidant, and antimicrobial activities of essential oil from pine needle (Cedrus deodara). J Food Sci 2012;77: C824-9. https://doi.org/10.1111/j.1750-3841.2012.02767.x

18. Ramay MS, Yalçın S. Effects of supplemental pine needles powder (Pinus brutia) on growth performance, breast meat composition, and antioxidant status in broilers fed linseed oil-based diets. Poult Sci 2020;99:479-86. https://doi.org/ $10.3382 / \mathrm{ps} / \mathrm{pez} 542$

19. Guo A, Cheng L, Al-Mamun M, Xiong C, Yang S. Effect of dietary pine needles powder supplementation on growth, organ weight and blood biochemical profiles in broilers. J Appl Anim Res 2018;46:518-22. https://doi.org/10.1080/09 712119.2017.1351977

20.Wu QJ, Wang ZB, Wang GY, Li YX, Qi YX. Effects of feed supplemented with fermented pine needles (Pinus ponderosa) on growth performance and antioxidant status in broilers. Poult Sci 2015;94:1138-44. https://doi.org/10.3382/ps/pev013

21. Kim YJ. Effects of dietary supplementation of pine needle powder on carcass characteristics and blood cholesterol contents of broiler chicken. Korean J Poult Sci 2011;38:51-7. https://doi.org/10.5536/KJPS.2011.38.1.051

22. Min BR, Solaiman S, Terrill T, Ramsay A, Mueller-Harvey I. The effects of tannins-containing ground pine bark diet upon nutrient digestion, nitrogen balance, and mineral retention in meat goats. J Anim Sci Biotechnol 2015;6:25. https://doi. org/10.1186/s40104-015-0020-5

23.Ni Z, Guo L, Liu F, Olatunji OJ, Yin M. Allium tuberosum alleviates diabetic nephropathy by supressing hyperglycemiainduced oxidative stress and inflammation in high fat diet/ streptozotocin treated rats. Biomed Pharmacother 2019;112: 108678. https://doi.org/10.1016/j.biopha.2019.108678

24. Kothari D, Lee WD, Jung ES, Niu KM, Lee CH, Kim SK. Controlled fermentation using autochthonous Lactobacillus plantarum improves antimicrobial potential of Chinese chives against poultry pathogens. Antibiotics 2020;9:386. https:// doi.org/10.3390/antibiotics 9070386

25.Tang X, Olatunji OJ, Zhou Y, Hou X. Allium tuberosum: antidiabetic and hepatoprotective activities. Food Res Int 2017;102:681-9. https://doi.org/10.1016/j.foodres.2017.08. 034

26.Putnik P, Gabrić D, Roohinejad S, et al. An overview of organosulfur compounds from Allium spp.: from processing and preservation to evaluation of their bioavailability, antimicrobial, and anti-inflammatory properties. Food Chem
2019;276:680-91. https://doi.org/10.1016/j.foodchem.2018. 10.068

27.AOAC. Official methods of analysis. 18th ed. Gaithersburg, MD, USA: Association of Official Analytical Chemists; 2005.

28. National Research Council. Nutrient requirements of poultry: ninth revised edition, 1994. Washington, DC, USA: The National Academies Press; 1994. https://doi.org/10.17226/ 2114

29. Kim DW, Kim JH, Kang GH, et al. Effects of water extract mixtures from Artemisia capillaris, Camellia sinensis, Schizandra chinensis, and Viscum album var. coloratum on laying performance, egg quality, blood characteristics, and egg storage stability in laying hens. Food Sci Anim Resour 2010;30:44957. https://doi.org/10.5851/kosfa.2010.30.3.449

30. Ma D, Shan A, Chen Z, et al. Effect of Ligustrum lucidum and Schisandra chinensis on the egg production, antioxidant status and immunity of laying hens during heat stress. Arch Anim Nutr 2005;59:439-47. https://doi.org/10.1080/1745039 0500353499

31.Goodarzi M, Nanekarani S, Landy N. Effect of dietary supplementation with onion (Allium cepa L.) on performance, carcass traits and intestinal microflora composition in broiler chickens. Asian Pac J Trop Dis 2014;4:S297-301. https://doi. org/10.1016/S2222-1808(14)60459-X

32.Li XL, He WL, Wang ZB, Xu TS. Effects of Chinese herbal mixture on performance, egg quality and blood biochemical parameters of laying hens. J Anim Physiol Anim Nutr 2016; 100:1041-9. https://doi.org/10.1111/jpn.12473

33. Kim CH, Paik IK. Effect of supplementary herbs and plant extracts on the performance of laying hens. Korean J Poult Sci 2008;35:71-8. https://doi.org/10.5536/KJPS.2008.35.1.071

34. Jones DR. Haugh unit: gold standard of egg quality. In: Proceedings of the National Egg Quality School; 2012 May 20-4: Indianapolis, IN USA. pp. 47-51.

35. Radwan Nadia L, Hassan RA, Qota EM, Fayek HM. Effect of natural antioxidant on oxidative stability of eggs and productive and reproductive performance of laying hens. Int J Poult Sci 2008;7:134-50. https://doi.org/10.3923/ijps.2008. 134.150

36. Abo Ghanima MM, Alagawany M, Abd El-Hack ME, et al. Consequences of various housing systems and dietary supplementation of thymol, carvacrol, and euganol on performance, egg quality, blood chemistry, and antioxidant parameters. Poult Sci 2020;99:4384-97. https://doi.org/10.1016/j.psj.2020. 05.028

37. Meyer E, Parsons C. The efficacy of a phytase enzyme fed to Hy-Line W-36 laying hens from 32 to 62 weeks of age. J Appl Poult Res 2011;20:136-42. https://doi.org/10.3382/japr.201000212

38. Kumar V, Sinha AK, Makkar HPS, De Boeck G, Becker K. Phytate and phytase in fish nutrition. J Anim Physiol Anim 
Nutr 2012;96:335-64. https://doi.org/10.1111/j.1439-0396. 2011.01169.x

39. Amad AA, Männer K, Wendler KR, Neumann K, Zentek J. Effects of a phytogenic feed additive on growth performance and ileal nutrient digestibility in broiler chickens. Poult Sci 2011;90:2811-6. https://doi.org/10.3382/ps.2011-01515

40. Hafeez A, Männer K, Schieder C, Zentek J. Effect of supplementation of phytogenic feed additives (powdered vs. encapsulated) on performance and nutrient digestibility in broiler chickens. Poult Sci 2016;95:622-9. https://doi.org/10.3382/ ps/pev368

41.Kim WH, Lillehoj HS. Immunity, immunomodulation, and antibiotic alternatives to maximize the genetic potential of poultry for growth and disease response. Anim Feed Sci Technol 2019;250:41-50. https://doi.org/10.1016/j.anifeedsci. 2018.09.016

42.Kothari D, Lee WD, Niu KM, Kim SK. The genus Allium as poultry feed additive: a review. Animals 2019;9:1032. https:// doi.org/10.3390/ani9121032 